\title{
From regenerative dentistry to regenerative medicine: progress, challenges, and potential applications of oral stem cells
}

This article was published in the following Dove Press journal:

Stem Cells and Cloning: Advances and Applications

4 December 2014

Number of times this article has been viewed

\section{Li Xiao'}

Masanori Nasu²

'Department of Pharmacology, ${ }^{2}$ Research Center, The Nippon Dental University, Tokyo, Japan
Correspondence: Li Xiao

Department of Pharmacology, The Nippon Dental University, School of Life Dentistry at Tokyo, I-9-20 Fujimi, Chiyoda-ku, Tokyo 102-8I59, Japan

Tel +8 I $3326 \mid 8772$

Fax +8I 332648399

Email xiaoli@tky.ndu.ac.jp
Abstract: Adult mesenchymal stem cells (MSCs) and epithelial stem cells play essential roles in tissue repair and self-healing. Oral MSCs and epithelial stem cells can be isolated from adult human oral tissues, for example, teeth, periodontal ligament, and gingiva. Cocultivated adult oral epithelial stem cells and MSCs could represent some developmental events, such as epithelial invagination and tubular structure formation, signifying their potentials for tissue regeneration. Oral epithelial stem cells have been used in regenerative medicine over 1 decade. They are able to form a stratified cell sheet under three-dimensional culture conditions. Both experimental and clinical data indicate that the cell sheets can not only safely and effectively reconstruct the damaged cornea in humans, but also repair esophageal ulcer in animal models Oral MSCs include dental pulp stem cells (DPSCs), stem cells from exfoliated deciduous teeth (SHED), stem cells from apical papilla (SCAP), periodontal ligament stem cells (PDLSCs), and mesenchymal stem cells from gingiva (GMSCs). They are widely applied in both regenerative dentistry and medicine. DPSCs, SHED, and SCAP are able to form dentin-pulp complex when being transplanted into immunodeficient animals. They have been experimentally used for the regeneration of dental pulp, neuron, bone muscle and blood vessels in animal models and have shown promising results. PDLSCs and GMSCs are demonstrated to be ideal cell sources for repairing the damaged tissues of periodontal, muscle, and tendon. Despite the abovementioned applications of oral stem cells, only a few human clinical trials are now underway to use them for the treatment of certain diseases. Since clinical use is the end goal, their true regenerative power and safety need to be further examined.

Keywords: oral mesenchymal stem cells, oral epithelial stem cells, cell transplantation, regeneration

\section{Introduction}

To restore the damaged tissues or organs, it is critical to understand the developmental process of specific tissues and then reproduce it. Stem cells play essential roles in organ development and tissue repair. In an organism, all the tissues are built from pluripotent embryonic stem cells. ${ }^{1}$ The embryonic stem cells differentiate into multipotent stem cells, including epithelial, mesenchymal, and other tissue-specific stem cells. ${ }^{2,3}$ Interactions among these stem cells initiate and regulate developmental processes, resulting in the formation of highly specialized functional tissues and organs. ${ }^{4,5}$ Once the organism matures, the pluripotent embryonic stem cells evanesce and some multipotent adult stem cells remain in the developed tissue to sustain the homeostasis and repair injuries ${ }^{6}$ (Figure 1). Many adult human tissues (such as bone marrow, ${ }^{7}$ dental pulp, ${ }^{8}$ adipose tissue, ${ }^{9}$ dermis, ${ }^{10}$ and umbilical cord $\left.^{11}\right)$ contain 


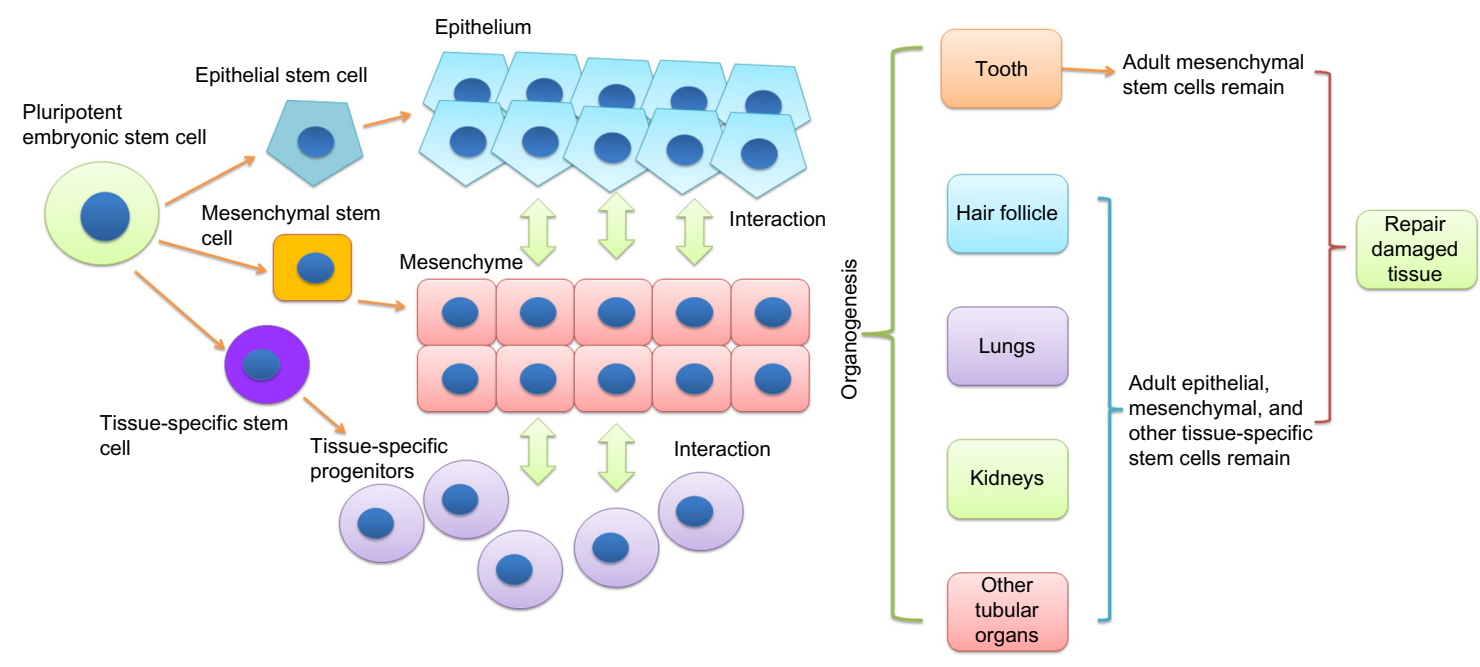

Figure I Diagram of stem cells and organogenesis.

populations of mesenchymal stem cells (MSCs). To date, the developmental origin of MSCs is still unclear. Although it is commonly considered that MSCs derive from mesodermal origin, ${ }^{12}$ evidence indicated that Sox $1^{+}$neuroepithelium and neural crest give rise to the earliest MSCs. ${ }^{13}$ In many postnatal tissues, MSCs are mainly located in the perivascular niche. ${ }^{14}$ Nevertheless, genetic lineage-tracing experiment showed that MSCs might have other localization. ${ }^{15}$ MSCs are able to differentiate into mature specific mesenchymal cells as well as adipocytes, chondrocytes, and osteoblasts under inductive stimuli. ${ }^{7,16}$ Additionally, MSCs can also give rise to nonmesenchymal cell lineages, such as endothelial cells, ${ }^{17}$ neuronal cells, ${ }^{18}$ and keratinocytes. ${ }^{19}$ Adult epithelial stem cells localized in the basal layer of various epithelial tissues such as skin epidermis and mucosal epithelium of the digestive and respiratory tracts. They are a dynamically heterogeneous cell population, ${ }^{20}$ have slow-cycling, ${ }^{21}$ retain long-term selfrenewal potential and can serve as a single stem-cell pool. ${ }^{22}$ Epithelial stem cells contribute the physiological renewal and wound healing in epithelial tissues by asymmetric divisions to generate the upper strata of the epidermis in skin ${ }^{23}$ or specialized cells in the simple epithelia of the gut (which has only one cell layer that contains different cell lineages). ${ }^{24}$ Transplantation and lineage-tracing experiments confirmed that epithelial stem cells give rise to not only all epithelial lineages ${ }^{25}$ but also neuroendocrine Merkel cells. ${ }^{26,27}$ MSCs and epithelial stem cells have been isolated from human oral tissues, including gingival, tooth, and periodontal ligament. ${ }^{8,28,29}$ Immunodeficient animal transplantation, preclinical trial, and in vitro differentiation assays demonstrated that these oral stem cells have strong potentials on various organs and tissues regeneration. Here, we will review current understanding of oral mesenchymal and epithelial stem cells and their prospective applications in both regenerative dentistry and medicine.

\section{Epithelial and mesenchymal stem cells regulate tooth development}

Teeth share similar developmental processes with many organs, such as lungs, kidneys, and hair follicle. Unlike the internal organs, the loss of teeth and artificial tooth extraction are not life-threatening. Therefore, teeth are excellent targets for the analysis of developmental mechanisms. The interactions between epithelial and mesenchymal stem cells initiate teeth development and regulate their morphogenesis. ${ }^{30}$ The details of epithelial-mesenchymal signaling in tooth development have been well documented by Thesleff et al. ${ }^{31,32}$ Here we focus on the fates of the epithelial and mesenchymal stem cells. In humans, tooth development begins in the middle of the sixth week of gestation. ${ }^{33}$ In an embryo, the basal cells of the dental lamina (dental epithelial tissue) undergo proliferation and form a horseshoe-shaped band that invaginates into the underlying mesenchymal tissue (this process is called epithelium invagination). ${ }^{34}$ The mesenchymal tissue, derived from neural crest cells, ${ }^{35}$ initiates the proliferation of the dental epithelial cells and directs them to finally differentiate into the enamel-producing cells, ameloblasts. Cells from the mesenchymal tissue react to the signals from dental epithelial cells. ${ }^{36}$ They differentiate into cementoblasts, periodontal ligament cells, odontoblasts, and other dental pulp cells (including neurons, endothelial cells, and fibroblasts). Once a functional tooth is formed, the dental epithelial cells no longer exist, whereas the mesenchymal cells remain in dental pulp and periodontal tissue (Figure 2) ${ }^{37}$ 


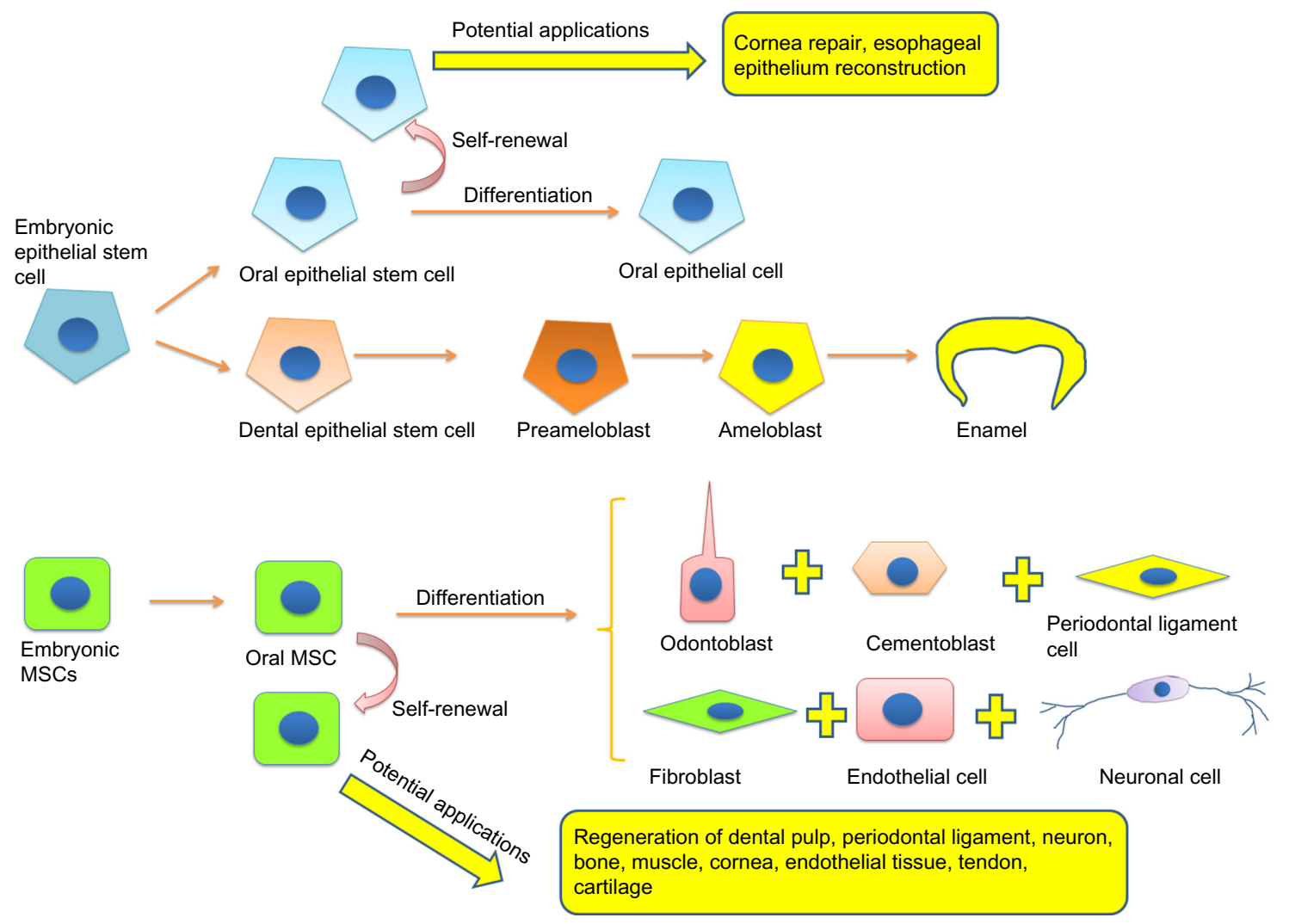

Figure 2 Differentiation of oral stem cells and their potential applications. Abbreviation: MSC, mesenchymal stem cell.

In 2007, Nakao et $\mathrm{al}^{38}$ rebuilt a bioengineered tooth using completely dissociated epithelial and mesenchymal stem cells from a mouse embryo. The bioengineered tooth could erupt from an immunodeficient mouse oral cave and develop into a functional tooth. ${ }^{39}$ Although their method is a breakthrough in tissue engineering, the clinical application is limited because it requires embryonic epithelial and mesenchymal stem cells. Using similar technology, they also regenerated functional hair follicle with adult epithelial and mesenchymal stem cells in immunodeficient mice. ${ }^{40}$ However, the hair follicle itself is a lifelong regenerative organ which is very different from most of the organs, including tooth and internal organs. The regeneration of tooth and internal organs (such as lungs and kidneys) with adult stem cells remains largely unexplored. We have reconstructed a three-dimensional epithelium invagination-like tissue model using human adult oral epithelial cells and dental pulp stem cells (DPSCs).$^{41}$ We also demonstrated that DPSCs-derived spheroids could mimic common developmental processes of tubular organs, including cavitation and spontaneous differentiation in vitro. ${ }^{42}$ Our data suggest that adult stem cells are able to represent some events of development under certain conditions that would provide an approach to the reconstruction of tooth and other organs by using adult epithelial and mesenchymal stem cells.

\section{Adult epithelial stem cells from oral tissue and their applications}

As we described earlier, the epithelial stem cells contribute toward tooth formation during development. Although it does not exist in developed human tooth, oral mucosal epithelium has drawn attention as an epithelial stem cell source for tissue engineering. In oral cavity, the mucosal epithelium covers the inner surface of the lips, floor of the mouth, gingiva, cheeks, hard palate, and tongue. Epithelial cells in the mucosal epithelium can be generally divided into three layers: basal, suprabasal, and superficial layers. Owing to the existence of epithelial progenitors in the basal layer, like most of the epithelial tissues (such as skin epidermis, intestinal crypt, and corneal limbus), the mucosal epithelium can constantly replace damaged or dead cells throughout the life of animals. These epithelial progenitors are characterized as quiescent and slow-cycling cells in vivo, ${ }^{43}$ as well as epithelial stem cells in other tissues. ${ }^{21}$ They express stem cell markers ( $\alpha 6$ and $\beta 1$ integrins, keratins 15 and 19, p63, $\alpha 6 \beta 4$, oct3/4, CD44H, p75, ATP-binding cassette subfamily G member 2 and K5) and give 
rise to cells in the suprabasal layer and finally differentiate into superficial epithelial cells. ${ }^{44}$ Because the epithelial tissues of the body share common molecular and cellular characteristics, unlike MSCs, identification of epithelial stem cells in vitro is based not on their ability of multidifferentiation but on their self-renewing capacity. The mucosal epithelial stem cells (or progenitors) can be isolated from oral tissues by using p75 antibody-based cell-sorting technique. When cultivated in vitro, they showed high clonogenicity and proliferative capacity. ${ }^{45}$ Under three-dimensional culture conditions, these oral epithelial progenitors are able to form a stratified cell sheet. Numerous studies have demonstrated that oral mucosal epithelial cell sheets promote corneal reconstruction when transplanted into the damaged sites. ${ }^{46,47}$ Autogenously grafted oral epithelial cell sheet has been used in patients with corneal limbal epithelial stem cell deficiency and was found to be safe and effective on corneal repair. ${ }^{48}$ Oral epithelial stem cells have also been used for the reconstruction of esophageal epithelium. Endoscopic transplantation of tissue-engineered autologous oral mucosal epithelial cell sheets was performed on esophageal ulcer in a canine model. The transplanted cell sheets were able to adhere to and survive on the underlying muscle layers in the ulcer sites, providing an intact, stratified epithelium. ${ }^{49}$ This evidence suggests that oral epithelial stem cells have the capacity to repair damaged epithelial tissues in the body. It has been reported that a collagen vitrigel sponge scaffold could promote regenerations of cornea and tracheal epithelium. ${ }^{50,51}$ A combination of oral mucosal epithelial cell sheet and the vitrigel scaffold might be a promising strategy for regeneration of various organs.

Despite these considerable regenerative applications of oral epithelial stem cells, numerous studies have shown evidence about their tumorigenic properties. White et $\mathrm{al}^{52}$ demonstrated that oral epithelial stem cells contributed to oncogenic multipotency and metastasis that caused transgenic mice to develop multilineage tumors. Therefore, it is important to carefully test the carcinogenicity of oral epithelial stem cells before their clinical transplantation.

\section{Adult MSCs from oral tissue and their applications Defining oral MSCs}

Oral MSCs can be broadly classified into two types: dental MSCs (which can form dentin-pulp complex in vivo) and nondental MSCs (which cannot form dentin-pulp complex). The dental MSCs include DPSCs, ${ }^{8}$ stem cells from exfoliated deciduous teeth (SHED), ${ }^{53}$ and stem cells from apical papilla (SCAP). ${ }^{54}$ Nondental oral MSCs include periodontal ligament stem cells (PDLSCs) ${ }^{55}$ and MSCs from gingiva (GMSCs). ${ }^{56}$ So far, there is no sole surface molecule to identify MSCs from oral tissues. The expression of common MSC markers, such as STRO-1, p75, Oct-4, SOX-2, SSEA-4, CD29, CD44, CD73, CD90, CD105, CD133, and CD146, have been used to partly identify their stemness. ${ }^{57}$ When being cultivated in vitro, they rapidly expand and display multipotency, with the capacity to give rise to osteo/odontogenic cells, chondrocytes, adipocytes, neuronal cells, muscle cells, cardiomyocytes, endothelial cells, hepatocyte-like cells, and islet-like cells. ${ }^{58-61}$ Because the behaviors of dental MSCs and nondental MSCs are different when being transplanted into immunodeficient animals, ${ }^{8,53-56}$ it is necessary to choose appropriate cells for different tissue regeneration. For example, dental MSCs are good for the regeneration of dentin-pulp complex, bone, cartilage, and neuronal tissues, whereas nondental oral MSCs are suitable for periodontal ligament tissue, tendon, and muscle repair.

\section{Dental pulp regeneration}

Dental pulp is a connective tissue that contains different types of cells, such as endothelial cells, neurons, fibroblasts, and odontoblasts. Dental pulp is surrounded by a thin layer of dentin matrix and dentin in the pulp chamber. The blood supply to dental pulp is through the apical foramen at the end of the pulp chamber. ${ }^{33}$ Since the diameter of apical foramen is only about $250 \mu \mathrm{m}$, the microenvironment of dental pulp lacks oxygen and nutrition, which is good for stem cell maintenance ${ }^{62}$ but bad for the infection control. Once the dental pulp is infected with pathogens by trauma or caries, it is difficult to remove the pathogens through antimicrobial therapies, often resulting in the extirpation of the whole pulp. Since dental pulp has numerous functions (such as nutritive, protective, reparative, and sensory) in the maintenance of teeth, regeneration of dental pulp has clinical needs.

Gronthos et $\mathrm{al}^{8}$ first isolated human DPSCs from dental pulp in impacted third molars. When in vitro expanded DPSCs were mixed with hydroxyapatite/tricalcium phosphate (HA/ TCP) ceramic powder and then transplanted into the dorsal surface of immunocompromised mice, a dentin-pulp-like complex was observed 6 weeks later. Other dental MSCs, such as SHED and SCAP, also showed the ability to generate the dentin-pulp-like complex after subcutaneous transplantation. ${ }^{53,54}$ However, no published reports have confirmed that PDLSCs and GMSCs could form a dentin-pulp-like complex under the same conditions, suggesting that the original location determines the fate of MSCs. Similar to HA/ TCP ceramic powder, human dentin also has been used as a carrier for dentin-pulp regeneration. Batouli et $\mathrm{al}^{63}$ loaded 
DPSCs onto a human dentin surface and then subcutaneously transplanted them into immunocompromised mice. At 8 weeks after transplantation, DPSCs were able to form a reparative dentin-like structure on the human dentin surface. Inside the dentin-like structure, blood vessels and connective tissue were observed, indicating dentin-pulp complex formation. Further study showed that the pretreatment of dentin could influence cellular behavior of subcutaneously transplanted DPSCs at the cell-dentin interface. On ethylenediaminetetraacetic acid (EDTA)-treated dentin cylinders, DPSCs could form a vascularized soft connective tissue similar to dental pulp, whereas on the NaOCl-treated dentin cylinders, DPSCs did not organize well. ${ }^{64}$ These data suggested that dental MSCs are able to regenerate dental pulp on calcific carriers under certain conditions. However, in most cases, transplanted stem cells survive only in vascularized places (such as subcutaneous tissue). Without an abundant blood supply, most transplanted stem cells will undergo necrotic or apoptotic cell death. Since dental pulp is housed in the pulp chamber, the blood supply can only come from the narrow apical foramen. Thus regenerating dental pulp inside the pulp chamber by transplanting dental MSCs remains a major challenge. A study showed that SHED and DPSCs could regenerate a pulp-like tissue in emptied root canal space (6-7 $\mathrm{mm}$ in length) with enlarged diameter $(>2 \mathrm{~mm})$ after subcutaneous transplantation. ${ }^{65}$ Since enlarged root canal passably increases the risk of infection, it is necessary to use different ways to increase angiogenesis and the viability of transplanted dental MSCs. Granulocyte-colony stimulating factor (G-CSF) showed stimulative effects on angiogenesis and stem cell mobilization. ${ }^{66,67}$ Iohara et $\mathrm{al}^{68}$ and Murakami et al ${ }^{69}$ demonstrated that G-CSF-treated DPSCs express a high level of trophic factors with properties of high proliferation, migration, and antiapoptotic effects and are endowed with regenerative potential. They transplanted G-CSF-mobilized autologous DPSCs with drugapproved G-CSF into dog pulpectomized tooth. At 14 days after transplantation, a pulp-like tissue with good vasculature and innervation was observed. The DPSCs differentiated into odontoblasts-like cells attached to the dentinal wall in the root canal and expressed enamelysin/matrix metalloproteinase 20, a marker for odontoblasts. Based on their results, a clinical trial has already been started in Japan. Although some safety issues need to be solved, the clinical applications of dental MSCs for pulp regeneration will not be far.

\section{Periodontal ligament tissue regeneration}

Periodontal ligament is the supporting tissue of tooth. It has the following functions: 1) suspends the tooth in its bony socket, the alveolus proper; 2) supplies nutrients to alveolus and cementum; 3) protects teeth; and 4) maintains homeostasis of teeth by PDLSCs. ${ }^{33}$ Periodontal disease or periodontitis is a disease with chronic inflammation-induced collapse of periodontal ligament tissue that often results in alveolar bone destruction, and eventually tooth loss. ${ }^{70}$ MSCs-based periodontal therapy has been demonstrated to inhibit inflammation, promote bone regeneration, and prevent tooth loss. ${ }^{71}$ Since PDLSCs are isolated from periodontal ligament, and they are able to generate typical cementum/periodontal ligament-like structure in vivo, they are considered as the first choice for periodontal ligament regeneration. Akizuki et $\mathrm{al}^{72}$ applied periodontal ligament cell sheets to dehiscence defects of the mesial roots in dogs. The cell sheet showed improvement in periodontal tissue healing with bone, periodontal ligament, and cementum formation. Ding et $\mathrm{al}^{73}$ reported that allogeneic PDLSC sheets could significantly stimulate periodontal tissue regeneration and cure inflammation in a miniature pig periodontitis model. The transplanted PDLSCs moderated the inflammatory response of periodontitis in part by suppressing the activation of both $\mathrm{T}$ cells and B cells. ${ }^{74}$ Vitamin $\mathrm{C}$ treatment was capable of inducing telomerase activity in PDLSCs, leading to a significant improvement in periodontal tissue regeneration compared with untreated control in a periodontal defects swine model. ${ }^{75}$

Oral MSCs derived from human gingiva (GMSCs) also have been considered as a promising alternative cell source for periodontal regeneration. ${ }^{76}$ In a class III furcation defects dog model, the transplanted GMSCs significantly enhanced the regeneration of the damaged periodontal tissue, including the alveolar bone, cementum, and functional periodontal ligament. ${ }^{77}$ Moreover, autologous DPSCs also have been used for periodontal regeneration in animal models and have shown promising results. ${ }^{78}$

\section{Neural regeneration}

Adult mammalian central nerve system (CNS) lacks regenerative power to replace the damaged neuronal cells (including neurons and glial cells) and reconstruct the dendritic connections. The reasons are considered to be that 1) neuronal progenitors have limited ability to regenerate functional neuronal cells; and 2) the local microenvironment, especially glial scar, inhibits neural regeneration. Transplanted stem cells therapy showed hopeful effects by providing neuronal progenitors and improving microenvironment in the injured site of CNS. ${ }^{79}$

Both dental and nondental MSCs are mainly derived from neural crest stem cells (which also give rise to 
neuronal cells). ${ }^{80}$ These two types of oral MSCs display neural crest stem cell features with expression of markers of neural progenitors, such as nestin, p75/NGFR, Pax6, and Tuj1. ${ }^{81,82}$ With neuronal stimulations, human dental MSCs (DPSCs, SHED, and SCAP) could differentiate into neural lineage in vitro. ${ }^{53,83,84}$ We observed that under a serum-free condition, human DPSCs are able to form spheroids with positive expression of neuronal progenitor marker HuC/D. Even without neuronal induction, gene expression of neural markers $C D H 2, N F M, T U B B 3$, and $C D 24$ in the spheroids were observed and increased in a culture time-dependent manner. ${ }^{85}$ It has been reported that when transplanted into the injured site of the CNS, DPSCs and SHED enhanced neuronal recovery in animal models of the CNS injuries. ${ }^{86,87}$ Although some studies showed evidence that DPSCs and SHED could differentiate into functional neurons with a voltage-gated, tetrodotoxin-sensitive inward current in vitro, ${ }^{83}$ expressed neuronal markers, and migrated into the CNS in vivo, ${ }^{53,88}$ most of the in vivo studies indicated that DPSCs and SHED did not differentiate into functional neuronal cells in the lesion site of animal models. The improvement of DPSCs and SHED on neuronal recovery is likely due to their neurotrophic products. ${ }^{89}$ Moreover, implanted DPSCs and SHED directly inhibited multiple axon growth inhibitor signals generated by the glial scar, suggesting that they can improve the microenvironment. ${ }^{90}$ To date, there is no in vivo study about the effect of SCAP and nondental MSCs (PDLSCs and GMSCs) on neuronal repair.

\section{Bone regeneration}

Bone development involves the aggregation of MSCs into mesenchymal condensations, which is partly similar to tooth development but without the epithelial invagination. There are two types of bone formation: intramembranous and endochondral. In endochondral bone formation, the mesenchymal condensations first undergo chondrogenesis and then ossification to form cartilage and bone. ${ }^{91}$ During adulthood, bone possesses the intrinsic capacity for regeneration throughout life. In most bone injuries (fractures), the damaged bone tissue can be functionally regenerated by the local cells (including chondroblasts, osteoblasts, endotheliocytes, and fibroblasts). However, when the fractures are serious (such as large bone defects created by trauma, infection, tumor resection, and skeletal abnormalities) enough that self-healing cannot repair, an adequate supply of stem cells (such as bone marrow stem cells) is required for efficient bone regeneration. ${ }^{92}$ Oral MSCs seem to be ideal candidates for bone regeneration. Both dental and nondental MSCs are able to differentiate into chondroblasts and osteoblasts under inductive conditions in vitro. ${ }^{93-96}$ An in vivo study showed that human DPSCs generated both osteoblasts and endotheliocytes, and eventually formed a bone-like structure with an integral blood supply similar to that of human adult bone in immunocompromised rats. ${ }^{97}$ Zheng et al ${ }^{98}$ reported that stem cells from miniature pig deciduous teeth were able to regenerate bone to repair critical-size mandibular defects in a swine model. In a clinical study, DPSCs and collagen sponge scaffold formed a biocomplex that could completely restore mandible bone defects in patients. ${ }^{99}$ Seo et $\mathrm{al}^{100}$ reported that SHED were able to repair the defects with substantial bone formation on the calvaria of immunocompromised mice. They also tested the bone regeneration capacity of PDLSCs and GMSCs encapsulated in a novel RGD (arginine-glycine-aspartic acid tripeptide)-coupled alginate microencapsulation system both in vitro and in vivo. Results confirmed that PDLSCs were able to repair the calvarial defects by promoting the formation of mineralized tissue, while GMSCs showed a significantly lesser osteogenic differentiation capability. ${ }^{101}$

\section{Muscle regeneration}

Some research groups have focused on the muscle- and tendon-forming properties of oral stem cells. Armiñán et $\mathrm{al}^{102}$ first reported that DPSCs could differentiate into cardiomyocyte-like cells when cocultivated with neonatal rat cardiomyocytes for about 4 weeks in vitro. Yang et al ${ }^{103}$ demonstrated that DPSCs were able to differentiate into dystrophin-producing muscle cells in cardiotoxin-paralyzed muscles in a mouse model, which has implications for the study and treatment of muscular dystrophy.

\section{Tendon and cartilage regeneration}

Tendons have very limited ability for self-repair after injuries. Since periodontal ligaments are similar to tendons (they both have the ability to absorb mechanical forces of stress and strain), PDLSCs have been used for tendon regeneration. Gronthos et $\mathrm{al}^{104}$ reported that ovine PDLSCs express scleraxis, a tendon-specific transcription factor in vitro. A recent study by the same group demonstrated that human PDLSCs and GMSCs encapsulated in RGD-coupled alginate microspheres, loaded with TGF- $\beta 3$, could form tendon-like tissue after subcutaneous transplantation into immunocompromised mice. Compared with GMSCs and human bone marrow MSCs, PDLSCs showed a more organized structure, with more extracellular matrix and collagen, suggesting PDLSCs have better potential for tendon regeneration. ${ }^{105}$ 
Cartilage (especially articular cartilage) also has very limited regenerative power. The treatment of cartilage injuries remains one of the most difficult challenges. ${ }^{106}$ Cell sheet technology has achieved robust cartilage repair in animal models. ${ }^{107,108}$ A clinical study has just started in Japan by implanting cartilaginous cell sheets to patients. ${ }^{109}$ PDLSCs and GMSCs have shown potential for cartilage regeneration. Moshaverinia et $\mathrm{al}^{110}$ reported that RGD-coupled alginate hydrogel can be used to encapsulate PDLSCs and GMSCs for cartilage regeneration. After 4 weeks of chondrogenic induction in vitro, PDLSCs and GMSCs differentiated into chondrocyte-like cells. In animal studies, ectopic cartilage tissue regeneration was observed in the areas of transplanted RGD-PDLSCs and RGD-GMSCs. Although some studies demonstrated that DPSCs could express cartilaginous markers after induction, ${ }^{111,112}$ to date there is no report about the in vivo study.

\section{Other regeneration}

DPSCs have been demonstrated to have therapeutic potential for ischemic injuries. An in vivo study showed that DPSCs could increase angiogenesis and reduce infarct size in rats with acute myocardial infarction. However, the transplanted DPSCs did not differentiate into endothelial cells, smooth muscle cells, or cardiac muscle cells within the infarct, suggesting that DPSCs possibly stimulated angiogenesis through secretion of paracrine factors. ${ }^{113}$ In models of mouse hind-limb ischemia, local transplantation of a highly vasculogenic subfraction of side population cells from dental pulp resulted in successful engraftment and an increase in the blood flow, including high density of capillary formation. In situ hybridization results showed that transplated DPSCs express an angiogenic marker (VEGF-A), chemokines (G-CSF, GM-CSF, CXCR4), and matrix-degrading enzymes (MMP1, MMP3) in the ischemic region 7 days after transplantation, implying that DPSCs promote neovascularization by paracrine actions of proangiogenic and chemotactic cytokines. ${ }^{114}$

Govindasamy et $\mathrm{al}^{115}$ explored the potential of DPSCs to differentiate into pancreatic cell lineage resembling isletlike cell aggregates in vitro. They demonstrated that DPSCs could differentiate into islet-like cell aggregates with positive expression of pancreatic markers C-peptide, Pdx-1, Pax4, Pax6, Ngn3, and Isl-1. Ishkitiev et al ${ }^{59}$ reported that CD117 SHED and DPSCs could differentiate into a pancreatic lineage in serum-free conditions. After pancreatic differentiation in vitro, the expression of pancreatic-specific endocrine markers insulin, glucagon, somatostatin, and pancreatic
Table I Oral stem cells and their regenerative applications

\begin{tabular}{|c|c|c|c|}
\hline Cells & Location & $\begin{array}{l}\text { Regenerative } \\
\text { applications (in vivo) }\end{array}$ & $\begin{array}{l}\text { Neoplasm } \\
\text { formation }\end{array}$ \\
\hline $\begin{array}{l}\text { Epithelial } \\
\text { stem cells }\end{array}$ & $\begin{array}{l}\text { Gingival and } \\
\text { other oral } \\
\text { epithelium }\end{array}$ & $\begin{array}{l}\text { Cornea repair, esophageal } \\
\text { epithelium reconstruction }\end{array}$ & Negative \\
\hline \multicolumn{4}{|c|}{ Oral MSCs } \\
\hline \multicolumn{4}{|c|}{ Dental MSCs } \\
\hline DPSC & Dental pulp & $\begin{array}{l}\text { Dental pulp, periodontal } \\
\text { ligament, neural, bone, } \\
\text { muscle, cornea, endothelial }\end{array}$ & Negative \\
\hline SHED & $\begin{array}{l}\text { Immature } \\
\text { dental pulp }\end{array}$ & $\begin{array}{l}\text { Dental pulp regeneration, } \\
\text { neural, bone }\end{array}$ & Negative \\
\hline SCAP & Apical papilla & & \\
\hline \multicolumn{4}{|c|}{ Nondental MSCs } \\
\hline PDLSC & $\begin{array}{l}\text { Periodontal } \\
\text { ligament }\end{array}$ & $\begin{array}{l}\text { Periodontal ligament, } \\
\text { bone, tendon, cartilage }\end{array}$ & Negative \\
\hline GMSC & Gingival & & \\
\hline
\end{tabular}

Abbreviations: DPSC, dental pulp stem cells; GMSC, mesenchymal stem cells from gingiva; MSCs, mesenchymal stem cells; PDLSC, periodontal ligament stem cells; SCAP, stem cells from apical papilla; SHED, stem cells from exfoliated deciduous teeth.

polypeptide, and exocrine marker alpha amylase-2a were detected by real-time reverse-transcription polymerase chain reaction in both SHED and DPSCs. A recent report showed that rat dental pulp cells could be converted into insulin-producing cells in vitro after being transfected with the transcription factors $\mathrm{Pdx} 1$ and Neurog $3 .^{60}$

Ishkitiev et al ${ }^{61116,117}$ also reported that $\mathrm{CD} 117^{+}$SHED and DPSCs were able to differentiate into hepatocyte-like cells under both serum-containing and serum-free conditions in vitro, implying that SHED and DPSCs can be potential sources for hepatocyte regeneration. This hepatic differentiation of DPSCs and SHED could be promoted by an oral malodorous compound, hydrogen sulfide (H(2)S). ${ }^{118}$

Moreover, human immature DPSCs (hIDPSCs) have been used for ocular surface reconstruction. Gomes et $\mathrm{al}^{119}$ transplanted a tissue-engineered hIDPSCs sheet onto the corneal bed of a rabbit model of total limbal stem cell deficiency. After 3 months, hIDPSC transplantation improved functional corneal regeneration and integrated into the local ocular tissue.

\section{Conclusion}

Oral epithelial and mesenchymal stem cells are easily obtained as discarded biological materials. Their excellent regenerative ability can be applied not only in dentistry but also in various fields of regenerative medicine. As we conclude in Table 1, oral stem cells show their capability to repair cornea, dental pulp, periodontal, neural, bone, muscle, tendon, cartilage, and endothelial tissues without neoplasm formation. However, despite these experimental 
studies demonstrating the regenerative potential of oral stem cells, most of the studies lack strict quantitative analysis for testing the ability of these cells to self-renew, proliferate, and differentiate, especially in vivo. Moreover, before their clinical application, the experimental studies need to resolve the following issues: 1) massive cell death in the transplanted site (it has been reported that in the damaged spinal cord only a few percent of the transplanted oral stem cells could survive, and they have difficulty to integrate into the local tissue; ${ }^{89}$ therefore, viability and functional differentiation of oral stem cells in vivo need to be improved); particularly for neuronal regeneration, 2) the interaction between transplanted oral stem cells and local cells or microenvironment needs to be analyzed; 3 ) in vivo cell lineage tracing of transplanted oral stem cells is required for understanding their fate and behavior; 4) since oral stem cells, especially oral epithelial stem cells, are often involved in neoplasia, the cellular and molecular mechanisms that allow oral stem cells to choose self-renewal, canceration, and differentiation should be well studied.

Furthermore, although these experimental assays are very informative to discover the features of oral stem cells, they do not exactly reflect the physiological and pathological conditions of the damaged tissues in human body. Up to now, only a few human clinical trials are underway to use oral stem cells for the regeneration of cornea, dental pulp, and bone. For the confirmation of their true regenerative power, double-blind randomized controlled trials need to be performed. As the clinical trials require a large number of clinical-grade cells in a short time, banking and manufacturing of oral stem cells are the deal strategies for clinical use. In the light of present research, there are two approaches for preserving oral stem cells: cryopreservation and magnetic freezing. Both the approaches can successfully store oral stem cells for a long time ( $>10$ years) with high cell survival rates after thawing. The procedure for banking oral stem cells is well described in an excellent review. ${ }^{120}$ Since Hiroshima University first established a commercial teeth bank in Japan in 2004, numerous biocompanies for teeth banking started business across more than 20 countries in America, Europe, and Asia. With the advanced preservation technology, dentistry will serve as a gateway to a wide variety of regenerative therapies by effectively using these valuable stem cell resources.

\section{Acknowledgments}

This work was supported in part by the Nippon Dental University Research Project 4 Grant and Japan Society for the Promotion of Science (JSPS) Grant-in-Aid for Scientific
Research (26861689). The authors thank Mr Nathaniel Green for proofreading.

\section{Disclosure}

The authors report no conflicts of interest in this work.

\section{References}

1. Behjati S, Huch M, van Boxtel R, et al. Genome sequencing of normal cells reveals developmental lineages and mutational processes. Nature. 2014;513:422-425.

2. Doetschman TC, Eistetter H, Katz M, Schmidt W, Kemler R. The in vitro development of blastocyst-derived embryonic stem cell lines: formation of visceral yolk sac, blood islands and myocardium. J Embryol Exp Morphol. 1985;87:27-45.

3. Odorico JS, Kaufman DS, Thomson JA. Multilineage differentiation from human embryonic stem cell lines. Stem Cells. 2001;19(3):193-204.

4. Aufderheide E, Chiquet-Ehrismann R, Ekblom P. Epithelial-mesenchymal interactions in the developing kidney lead to expression of tenascin in the mesenchyme. J Cell Biol. 1987;105(1):599-608.

5. Vainio S, Karavanova I, Jowett A, Thesleff I. Identification of BMP-4 as a signal mediating secondary induction between epithelial and mesenchymal tissues during early tooth development. Cell. 1993;75(1):45-58.

6. Kørbling M, Estrov Z. Adult stem cells for tissue repair-a new therapeutic concept? N Engl J Med. 2003;349(6):570-582.

7. Pittenger MF, Mackay AM, Beck SC, et al. Multilineage potential of adult human mesenchymal stem cells. Science. 1999;284(5411):143-147.

8. Gronthos S, Mankani M, Brahim J, Robey PG, Shi S. Postnatal human dental pulp stem cells (DPSCs) in vitro and in vivo. Proc Natl Acad Sci US A. 2000;97(25):13625-13630.

9. Strem BM, Hicok KC, Zhu M, et al. Multipotential differentiation of adipose tissue-derived stem cells. Keio J Med. 2005;54(3):132-141.

10. Joannides A, Gaughwin P, Schwiening C, et al. Efficient generation of neural precursors from adult human skin: astrocytes promote neurogenesis from skin-derived stem cells. Lancet. 2004;364(9429):172-178.

11. Bieback K, Kern S, Klüter H, Eichler H. Critical parameters for the isolation of mesenchymal stem cells from umbilical cord blood. Stem Cells. 2004;22(4):625-634.

12. Dennis JE, Charbord P. Origin and differentiation of human and murine stroma. Stem Cells. 2002;20(3):205-214.

13. Takashima Y, Era T, Nakao K, et al. Neuroepithelial cells supply an initial transient wave of MSC differentiation. Cell. 2007;129(7): 1377-1388.

14. Caplan AI. Adult mesenchymal stem cells for tissue engineering versus regenerative medicine. J Cell Physiol. 2007;213(2):341-347.

15. Feng J, Mantesso A, De Bari C, Nishiyama A, Sharpe PT. Dual origin of mesenchymal stem cells contributing to organ growth and repair. Proc Natl Acad Sci U SA. 2011;108(16):6503-6508.

16. Nombela-Arrieta C, Ritz J, Silberstein LE. The elusive nature and function of mesenchymal stem cells. Nat Rev Mol Cell Biol. 2011;12(2): $126-131$.

17. Oswald J, Boxberger S, Jørgensen B, et al. Mesenchymal stem cells can be differentiated into endothelial cells in vitro. Stem Cells. 2004;22(3):377-384.

18. Tropel P, Platet N, Platel JC, et al. Functional neuronal differentiation of bone marrow-derived mesenchymal stem cells. Stem Cells. 2006; 24(12):2868-2876.

19. Sasaki M, Abe R, Fujita Y, Ando S, Inokuma D, Shimizu H. Mesenchymal stem cells are recruited into wounded skin and contribute to wound repair by transdifferentiation into multiple skin cell type. J Immunol. 2008;180(4):2581-2587.

20. Legué E, Sequeira I, Nicolas JF. Hair follicle renewal: authentic morphogenesis that depends on a complex progression of stem cell lineages. Development. 2010;137(4):569-577. 
21. Takeda N, Jain R, LeBoeuf MR, Wang Q, Lu MM, Epstein JA. Interconversion between intestinal stem cell populations in distinct niches. Science. 2011;334(6061):1420-1424.

22. Ritsma L, Ellenbroek SI, Zomer A, et al. Intestinal crypt homeostasis revealed at single-stem-cell level by in vivo live imaging. Nature. 2014; 507(7492):362-365.

23. Plikus MV, Gay DL, Treffeisen E, Wang A, Supapannachart RJ, Cotsarelis G. Epithelial stem cells and implications for wound repair. Semin Cell Dev Biol. 2012;23(9):946-953.

24. Oshima H, Rochat A, Kedzia C, Kobayashi K, Barrandon Y. Morphogenesis and renewal of hair follicles from adult multipotent stem cells. Cell. 2001;104(2):233-245.

25. Barker N, Bartfeld S, Clevers H. Tissue-resident adult stem cell populations of rapidly self-renewing organs. Cell Stem Cell. 2010;7(6):656-670.

26. Morrison KM, Miesegaes GR, Lumpkin EA, Maricich SM. Mammalian Merkel cells are descended from the epidermal lineage. Dev Biol. 2009;336(1):76-83.

27. Van Keymeulen A, Mascre G, Youseff KK, et al. Epidermal progenitors give rise to Merkel cells during embryonic development and adult homeostasis. J Cell Biol. 2009;187(1):91-100.

28. Angelova Volponi A, Kawasaki M, Sharpe PT. Adult human gingival epithelial cells as a source for whole-tooth bioengineering. J Dent Res. 2013;92(4):329-334

29. Mrozik K, Gronthos S, Shi S, Bartold PM. A method to isolate, purify, and characterize human periodontal ligament stem cells. Methods Mol Biol. 2010;666:269-284.

30. Thesleff I, Partanen AM, Vainio S. Epithelial-mesenchymal interactions in tooth morphogenesis: the roles of extracellular matrix, growth factors, and cell surface receptors. J Craniofac Genet Dev Biol. 1991;11(4) 229-237.

31. Thesleff I, Vaahtokari A, Kettunen P, Aberg T. Epithelial-mesenchymal signaling during tooth development. Connect Tissue Res. 1995;32(1-4): 9-15.

32. Thesleff I. Epithelial-mesenchymal signalling regulating tooth morphogenesis. J Cell Sci. 2003;116(Pt 9):1647-1648.

33. Gartner LP. Oral Histology and Embryology. Baltimore, MD: Williams and Wilkins; 1989.

34. Goldberg M, editor. The Dental Pulp: Biology, Pathology, and Regenerative Therapies. Berlin, Heidelberg, NY: Springer; 2014.

35. Le Douarin NM, Creuzet S, Couly G, Dupin E. Neural crest cell plasticity and its limits. Development. 2004;131(19):4637-4650.

36. Dassule HR, Lewis P, Bei M, Maas R, McMahon AP. Sonic hedgehog regulates growth and morphogenesis of the tooth. Development. 2000;127(22):4775-4785.

37. Nanci A. Ten Cate's Oral Histology: Development, Structure, and Function. 7th ed. St Louis, MO: Mosby; 2007.

38. Nakao K, Morita R, Saji Y, et al. The development of a bioengineered organ germ method. Nat Methods. 2007;4(3):227-230.

39. Ikeda E, Morita R, Nakao K, et al. Fully functional bioengineered tooth replacement as an organ replacement therapy. Proc Natl Acad Sci USA. 2009;106(32):13475-13480.

40. Toyoshima KE, Asakawa K, Ishibashi N, et al. Fully functional hair follicle regeneration through the rearrangement of stem cells and their niches. Nat Commun. 2012;17(3):784.

41. Xiao L, Tsutsui T. Three-dimensional epithelial and mesenchymal cell cocultures form early tooth epithelium invagination-like structures: expression patterns of relevant molecules. J Cell Biochem. 2012;113(6):1875-1885.

42. Xiao L, Kumazawa Y, Okamura H. Cell death, cavitation and spontaneous multi-differentiation of dental pulp stem cells-derived spheroids in vitro: a journey to survival and organogenesis. Biol Cell. Epub August 29, 2014.

43. Nakamura T, Endo K, Kinoshita S. Identification of human oral keratinocyte stem/progenitor cells by neurotrophin receptor $\mathrm{p} 75$ and the role of neurotrophin/p75 signaling. Stem Cells. 2007;25(3):628-638.

44. Jones KB, Klein OD. Oral epithelial stem cells in tissue maintenance and disease: the first steps in a long journey. Int J Oral Sci. 2013;5(3): 121-129.
45. Sen S, Sharma S, Gupta A, et al. Molecular characterization of explant cultured human oral mucosal epithelial cells. Invest Ophthalmol Vis Sci. 2011;52(13):9548-9554.

46. Nishida K, Yamato M, Hayashida Y, et al. Corneal reconstruction with tissue-engineered cell sheets composed of autologous oral mucosal epithelium. N Engl J Med. 2004;351(12):1187-1196.

47. Ma DH, Kuo MT, Tsai YJ, et al. Transplantation of cultivated oral mucosal epithelial cells for severe corneal burn. Eye (Lond). 2009;23(6): 1442-1450.

48. Burillon C, Huot L, Justin V, et al. Cultured autologous oral mucosal epithelial cell sheet (CAOMECS) transplantation for the treatment of corneal limbal epithelial stem cell deficiency. Invest Ophthalmol Vis Sci. 2012;53(3):1325-1331.

49. Ohki T, Yamato M, Murakami D, et al. Treatment of oesophageal ulcerations using endoscopic transplantation of tissue-engineered autologous oral mucosal epithelial cell sheets in a canine model. Gut. 2006;55(12): 1704-1710.

50. McIntosh Ambrose W, Salahuddin A, So S, et al. Collagen Vitrigel membranes for the in vitro reconstruction of separate corneal epithelial, stromal, and endothelial cell layers. J Biomed Mater Res B Appl Biomater. 2009;90(2):818-831.

51. Tani A, Tada Y, Takezawa T, et al. Regeneration of tracheal epithelium using a collagen vitrigel-sponge scaffold containing basic fibroblast growth factor. Ann Otol Rhinol Laryngol. 2012;121(4): 261-268.

52. White RA, Neiman JM, Reddi A, et al. Epithelial stem cell mutations that promote squamous cell carcinoma metastasis. J Clin Invest. 2013;123(10):4390-4404

53. Miura M, Gronthos S, Zhao M, et al. SHED: stem cells from human exfoliated deciduous teeth. Proc Natl Acad Sci U S A. 2003;100(10): 5807-5812.

54. Huang GT, Sonoyama W, Liu Y, Liu H, Wang S, Shi S. The hidden treasure in apical papilla: the potential role in pulp/dentin regeneration and bioroot engineering. J Endod. 2008;34(6):645-651.

55. Seo BM, Miura M, Gronthos S, et al. Investigation of multipotent postnatal stem cells from human periodontal ligament. Lancet. 2004; 364(9429):149-155.

56. Zhang Q, Shi S, Liu Y, et al. Mesenchymal stem cells derived from human gingiva are capable of immunomodulatory functions and ameliorate inflammation-related tissue destruction in experimental colitis. J Immunol. 2009;183(12):7787-7798.

57. Mao JJ, Prockop DJ. Stem cells in the face: tooth regeneration and beyond. Cell Stem Cell. 2012;11(3):291-301.

58. Huang GT, Gronthos S, Shi S. Mesenchymal stem cells derived from dental tissues vs those from other sources: their biology and role in regenerative medicine. J Dent Res. 2009;88(9):792-806.

59. Ishkitiev N, Yaegaki K, Kozhuharova A, et al. Pancreatic differentiation of human dental pulp CD117+ ${ }^{+}$stem cells. Regen Med. 2013;8(5): 597-612.

60. Nozaki T, Ohura K. Regulation of miRNA during direct reprogramming of dental pulp cells to insulin-producing cells. Biochem Biophys Res Commun. 2014;444(2):195-198.

61. Ishkitiev N, Yaegaki K, Imai T, et al. High-purity hepatic lineage differentiated from dental pulp stem cells in serum-free medium. J Endod. 2012;38(4):475-480.

62. Cipolleschi MG, Dello Sbarba P, Olivotto M. The role of hypoxia in the maintenance of hematopoietic stem cells. Blood. 1993;82(7): 2031-2037.

63. Batouli S, Miura M, Brahim J, et al. Comparison of stem-cell-mediated osteogenesis and dentinogenesis. J Dent Res. 2003;82(12):976-981.

64. Galler KM, D'Souza RN, Federlin M, et al. Dentin conditioning codetermines cell fate in regenerative endodontics. J Endod. 2011;37(11): $1536-1541$

65. Huang GT, Yamaza T, Shea LD, et al. Stem/progenitor cell-mediated de novo regeneration of dental pulp with newly deposited continuous layer of dentin in an in vivo model. Tissue Eng Part A. 2010;16(2): 605-615. 
66. Natori T, Sata M, Washida M, Hirata Y, Nagai R, Makuuchi M. G-CSF stimulates angiogenesis and promotes tumor growth: potential contribution of bone marrow-derived endothelial progenitor cells. Biochem Biophys Res Commun. 2002;297(4):1058-1061.

67. Ieda Y, Fujita J, Ieda M, et al. G-CSF and HGF: combination of vasculogenesis and angiogenesis synergistically improves recovery in murine hind limb ischemia. J Mol Cell Cardiol. 2007;42(3):540-548.

68. Iohara K, Murakami M, Takeuchi N, et al. A novel combinatorial therapy with pulp stem cells and granulocyte colony-stimulating factor for total pulp regeneration. Stem Cells Transl Med. 2013;2(7): 521-533.

69. Murakami M, Horibe H, Iohara K, et al. The use of granulocyte-colony stimulating factor induced mobilization for isolation of dental pulp stem cells with high regenerative potential. Biomaterials. 2013;34(36): 9036-9047.

70. Tatakis DN, Kumar PS. Etiology and pathogenesis of periodontal diseases. Dent Clin North Am. 2005;49(3):491-516.

71. Racz GZ, Kadar K, Foldes A, et al. Immunomodulatory and potential therapeutic role of mesenchymal stem cells in periodontitis. J Physiol Pharmacol. 2014;65(3):327-339.

72. Akizuki T, Oda S, Komaki M, et al. Application of periodontal ligament cell sheet for periodontal regeneration: a pilot study in beagle dogs. J Periodontal Res. 2005;40(3):245-251.

73. Ding G, Liu Y, Wang W, et al. Allogeneic periodontal ligament stem cell therapy for periodontitis in swine. Stem Cells. 2010;28(10): $1829-1838$

74. Liu O, Xu J, Ding G, et al. Periodontal ligament stem cells regulate B lymphocyte function via programmed cell death protein 1. Stem Cells. 2013;31(7):1371-1382.

75. Wei F, Qu C, Song T, et al. Vitamin C treatment promotes mesenchymal stem cell sheet formation and tissue regeneration by elevating telomerase activity. J Cell Physiol. 2012;227(9):3216-3224.

76. Yang H, Gao LN, An Y, et al. Comparison of mesenchymal stem cells derived from gingival tissue and periodontal ligament in different incubation conditions. Biomaterials. 2013;34(29):7033-7047.

77. Yu X, Ge S, Chen S, et al. Human gingiva-derived mesenchymal stromal cells contribute to periodontal regeneration in beagle dogs. Cells Tissues Organs. 2013;198(6):428-437.

78. Khorsand A, Eslaminejad MB, Arabsolghar M, et al. Autologous dental pulp stem cells in regeneration of defect created in canine periodontal tissue. J Oral Implantol. 2013;39(4):433-443.

79. Horner PJ, Gage FH. Regenerating the damaged central nervous system. Nature. 2000;407(6807):963-970.

80. Xiao L, Tsutsui T. Human dental mesenchymal stem cells and neural regeneration. Hum Cell. 2013;26(3):91-96.

81. Huang L, Liang J, Geng Y, et al. Directing adult human periodontal ligament-derived stem cells to retinal fate. Invest Ophthalmol Vis Sci. 2013;54(6):3965-3974.

82. Xu X, Chen C, Akiyama K, et al. Gingivae contain neural-crest- and mesoderm-derived mesenchymal stem cells. J Dent Res. 2013;92(9): $825-832$.

83. Arthur A, Rychkov G, Shi S, Koblar SA, Gronthos S. Adult human dental pulp stem cells differentiate toward functionally active neurons under appropriate environmental cues. Stem Cells. 2008;26(7):1787-1795.

84. Sonoyama W, Liu Y, Yamaza T, et al. Characterization of the apical papilla and its residing stem cells from human immature permanent teeth: a pilot study. J Endod. 2008;34(2):166-171.

85. Xiao L, Tsutsui T. Characterization of human dental pulp cells-derived spheroids in serum-free medium: stem cells in the core. J Cell Biochem. 2013;114(11):2624-2636.

86. Yang KL, Chen MF, Liao CH, Pang CY, Lin PY. A simple and efficient method for generating Nurr1-positive neuronal stem cells from human wisdom teeth (tNSC) and the potential of $\mathrm{tNSC}$ for stroke therapy. Cytotherapy. 2009;11(5):606-617.

87. Yamagata M, Yamamoto A, Kako E, et al. Human dental pulp-derived stem cells protect against hypoxic-ischemic brain injury in neonatal mice. Stroke. 2013;44(2):551-554.
88. Wang J, Wei X, Ling J, Huang Y, Gong Q, Huo Y. Identification and characterization of side population cells from adult human dental pulp after ischemic culture. J Endod. 2012;38(11):1489-1497.

89. Sakai K, Yamamoto A, Matsubara K, et al. Human dental pulp-derived stem cells promote locomotor recovery after complete transection of the rat spinal cord by multiple neuro-regenerative mechanisms. J Clin Invest. 2012;122(1):80-90.

90. Mead B, Logan A, Berry M, Leadbeater W, Scheven BA. Intravitreally transplanted dental pulp stem cells promote neuroprotection and axon regeneration of retinal ganglion cells after optic nerve injury. Invest Ophthalmol Vis Sci. 2013;54(12):7544-7556.

91. Khurana JS. Bone pathology. 2nd ed. Philadephia, PA: Springer; 2009.

92. Dimitriou R, Jones E, McGonagle D, Giannoudis PV. Bone regeneration: current concepts and future directions. BMC Med. 2011;9:66.

93. Yamada Y, Ito K, Nakamura S, Ueda M, Nagasaka T. Promising cellbased therapy for bone regeneration using stem cells from deciduous teeth, dental pulp, and bone marrow. Cell Transplant. 2011;20(7): 1003-1013.

94. Graziano A, d'Aquino R, Laino G, Papaccio G. Dental pulp stem cells: a promising tool for bone regeneration. Stem Cell Rev. 2008;4(1): 21-26.

95. Mori G, Brunetti G, Oranger A, et al. Dental pulp stem cells: osteogenic differentiation and gene expression. Ann N Y Acad Sci. 2011;1237: 47-52.

96. Chadipiralla K, Yochim JM, Bahuleyan B, et al. Osteogenic differentiation of stem cells derived from human periodontal ligaments and pulp of human exfoliated deciduous teeth. Cell Tissue Res. 2010;340(2):323-333.

97. d'Aquino R, Graziano A, Sampaolesi M, et al. Human postnatal dental pulp cells co-differentiate into osteoblasts and endotheliocytes: a pivotal synergy leading to adult bone tissue formation. Cell Death Differ. 2007;14(6):1162-1171.

98. Zheng Y, Liu Y, Zhang CM, et al. Stem cells from deciduous tooth repair mandibular defect in swine. J Dent Res. 2009;88(3):249-254.

99. d'Aquino R, De Rosa A, Lanza V, et al. Human mandible bone defect repair by the grafting of dental pulp stem/progenitor cells and collagen sponge biocomplexes. Eur Cell Mater. 2009;18:75-83.

100. Seo BM, Sonoyama W, Yamaza T, et al. SHED repair critical-size calvarial defects in mice. Oral Dis. 2008;14(5):428-434.

101. Moshaverinia $\mathrm{A}, \mathrm{Chen} \mathrm{C}, \mathrm{Xu} \mathrm{X}$, et al. Bone regeneration potential of stem cells derived from periodontal ligament or gingival tissue sources encapsulated in RGD-modified alginate scaffold. Tissue Eng Part A. 2014;20(3-4):611-621.

102. Armiñán A, Gandía C, Bartual M, et al. Cardiac differentiation is driven by NKX2.5 and GATA4 nuclear translocation in tissue-specific mesenchymal stem cells. Stem Cells Dev. 2009;18(6):907-918.

103. Yang R, Chen M, Lee CH, Yoon R, Lal S, Mao JJ. Clones of ectopic stem cells in the regeneration of muscle defects in vivo. PLoS One. 2010;5(10):e13547.

104. Gronthos S, Mrozik K, Shi S, Bartold PM. Ovine periodontal ligament stem cells: isolation, characterization, and differentiation potential. Calcif Tissue Int. 2006;79(5):310-317.

105. Moshaverinia A, Xu X, Chen C, et al. Application of stem cells derived from the periodontal ligament or gingival tissue sources for tendon tissue regeneration. Biomaterials. 2014;35(9):2642-2650.

106. Orth P, Rey-Rico A, Venkatesan JK, Madry H, Cucchiarini M. Current perspectives in stem cell research for knee cartilage repair. Stem Cells Cloning. 2014;7:1-17.

107. Ebihara G, Sato M, Yamato M, et al. Cartilage repair in transplanted scaffold-free chondrocyte sheets using a minipig model. Biomaterials. 2012;33(15):3846-3851.

108. Yan H, Yu C. Repair of full-thickness cartilage defects with cells of different origin in a rabbit model. Arthroscopy. 2007;23(2):178-187.

109. Sato M, Yamato M, Hamahashi K, Okano T, Mochida J. Articular cartilage regeneration using cell sheet technology. Anat Rec (Hoboken). 2014;297(1):36-43. 
110. Moshaverinia A, Xu X, Chen C, Akiyama K, Snead ML, Shi S. Dental mesenchymal stem cells encapsulated in an alginate hydrogel co-delivery microencapsulation system for cartilage regeneration. Acta Biomater. 2013;9(12):9343-9350.

111. Rizk A, Rabie AB. Human dental pulp stem cells expressing transforming growth factor $\beta 3$ transgene for cartilage-like tissue engineering. Cytotherapy. 2013;15(6):712-725.

112. Yu J, He H, Tang C, et al. Differentiation potential of STRO-1+ dental pulp stem cells changes during cell passaging. BMC Cell Biol. 2010;11:32.

113. Gandia C, Armiñan A, García-Verdugo JM, et al. Human dental pulp stem cells improve left ventricular function, induce angiogenesis, and reduce infarct size in rats with acute myocardial infarction. Stem Cells. 2008;26(3):638-645.

114. Iohara K, Zheng L, Wake H, et al. A novel stem cell source for vasculogenesis in ischemia: subfraction of side population cells from dental pulp. Stem Cells. 2008;26(9):2408-2418.

115. Govindasamy V, Ronald VS, Abdullah AN, et al. Differentiation of dental pulp stem cells into islet-like aggregates. J Dent Res. 2011; 90(5):646-652.
116. Ishkitiev N, Calenic B, Aoyama I, Ii H, Yaegaki K, Imai T. Hydrogen sulfide increases hepatic differentiation in tooth-pulp stem cells. $J$ Breath Res. 2012;6(1):017103.

117. Ishkitiev N, Yaegaki K, Calenic B, et al. Deciduous and permanent dental pulp mesenchymal cells acquire hepatic morphologic and functional features in vitro. J Endod. 2010;36(3):469-474.

118. Okada M, Ishkitiev N, Yaegaki K, et al. Hydrogen sulfide increases hepatic differentiation of human tooth-pulp stem cells compared with human bone-marrow stem cells. Int Endod J. 2014;47(12)1142-1150.

119. Gomes JA, Geraldes Monteiro B, Melo GB, et al. Corneal reconstruction with tissue-engineered cell sheets composed of human immature dental pulp stem cells. Invest Ophthalmol Vis Sci. 2010; 51(3):1408-1414.

120. Arora V, Arora P, Munshi AK. Banking stem cells from human exfoliated deciduous teeth (SHED): saving for the future. J Clin Pediatr Dent. 2009;33(4):289-294
Stem Cells and Cloning: Advances and Applications

\section{Publish your work in this journal}

Stem Cells and Cloning: Advances and Applications is an international, peer-reviewed, open access journal. Areas of interest in stem cell research include: Embryonic stem cells; Adult stem cells; Blastocysts; Cordblood stem cells; Stem cell transformation and culture; Therapeutic cloning; Umbilical cord blood and bone marrow cells; Laboratory,

\section{Dovepress}

animal and human therapeutic studies; Philosophical and ethical issues related to stem cell research. This journal is indexed on CAS. The manuscript management system is completely online and includes a quick and fair peer-review system. Visit http://www.dovepress.com/ testimonials.php to read real quotes from published authors.

Submit your manuscript here: http://www.dovepress.com/stem-cells-and-cloning-advances-and-applications-journal 